\title{
VORTEX DYNAMICS AND CRITICAL CURRENTS IN YBACUO SINGLE CRYSTAL WITH UNIDIRECTIONAL TWINS IN TILTED MAGNETIC FIELDS
}

M. El-Saadawy*

\begin{abstract}
We have measured resistive transitions and current-voltage characteristics for two samples having unidirectional twins oriented parallel and perpendicular with respect to transport current vector in tilted relatively to the c-axis magnetic fields. We observed glass-like behavior of the resistance at small transport currents for current vector oriented perpendicular to twin planes. The observed features of resistive behavior of both samples may be explained by special vortex dynamics in tilted fields.
\end{abstract}

* Department of Physics, Faculty of Education, Tanta University.

-1- 


\section{Introduction:}

Investigation of resistive transitions $\mathrm{R}(\mathrm{T})$ of $\mathrm{YBaCuO}$ superconductor in the presence of an external magnetic field $\mathrm{H}$ shows the existence near some temperature $\mathrm{T}_{\mathrm{sh}}$ of a downturn referred to as a shoulder. Current-voltage characteristics (CVCs) for $\mathrm{H}_{\mathrm{c}}$ are linear above $\mathrm{T}_{\mathrm{sh}}$ and nonlinear below $\mathrm{T}_{\mathrm{sh}}$. The temperature $\mathrm{T}_{\mathrm{sh}}$ is well below the mean-field transition temperature $\mathrm{T}_{\mathrm{c} 2}$ and well above the irreversibility line $T_{\text {irr. }}$. To date, it is supposed that above $T_{\text {sh }}$ an unpinned vortex fluid and below $\mathrm{T}_{\text {irr }}$ a vortex glass phase exists respectively. Theoretical investigations in weak ${ }^{(1)}$ and intermediate ${ }^{(2)}$ pinning regime show that below $\mathrm{T}_{\mathrm{sh}}$ then exist a partially pinned vortex-fluid phase. An alternative model ${ }^{(3)}$ interprets the shoulder as phase boundary between high-temperature isotropic and low temperature hexatic vortex liquid states.

The aim of this paper is to investigate the phase state and dissipation of vortex system in $\mathrm{YBaCuO}$ single crystals tilted relatively to the twins magnetic fields. We will present resistive transitions $\mathrm{R}(\mathrm{T})$ and current-voltage characteristics CVCs of a bridge (see inset in Fig. 1) cut out from $\mathrm{YBaCuO}$ single crystal having a cross section of $0.2 \times 0.015 \mathrm{~mm}^{2}$. Measurements were made in a magnetic field $\mathrm{H}=15 \mathrm{kOe}$. Transport current vector I was parallel to ab-plane, and was parallel to twin boundaries (TBs) in sample 1 (potential contacts 1 and 2) and perpendicular to TBs in sample 2 (potential contacts 3 and 4). The bridge could be rotated in the field around two axes and desirable orientation of $\mathrm{H}$ with respect to TBs could be achieved.

\section{Experimental procedures:}

Single crystals were prepared, as in a previous study ${ }^{(4)}$ grown in a bold crucible by the solution-melt technique with a low temperature gradient along the crucible. This method makes it possible to grow crystals with a size up to $5 \times 5 \mathrm{~mm}^{2}$ in the ab-plane and with a thickness 0.02-0.05 mm. The compounds $\mathrm{Y}_{2} \mathrm{O}_{3}, \mathrm{BaCO}_{3}, \mathrm{CuO}$, were used as initial components. The crystals were saturated with oxygen by annealing in oxygen flow for three days at $430{ }^{\circ} \mathrm{C}$. The resistivity of 
the samples subjected to such a thermal treatment was $\simeq 2 \times 10^{-6} \Omega . \mathrm{m}$ and a transition temperature $\mathrm{T}_{\mathrm{C}}=92.5 \mathrm{~K}$ with a transition width $\Delta \mathrm{T}_{\mathrm{c}} \approx$ $0.4 \mathrm{~K}$.

Electrical contacts were prepared by depositing silver paste on the crystal surface, followed by connecting silver wire and 3-h annealing in oxygen at $200^{\circ} \mathrm{C}$. The leads for current contacts were fabricated from foil of thickness $0.1 \mathrm{~mm}$ and width $3-4 \mathrm{~mm}$, while potential contacts were made of wire having a diameter of $0.05 \mathrm{~mm}$. Such a technology made it possible to obtain a low junction resistance in the contact and to carry out resistive measurements with a transport current up to 1.5 A without ohmic superheating in current contacts. After saturation with oxygen and fabrication of electric contacts, a bridge was cut of a crystal of thickness $0.02 \mathrm{~mm}$ as shown in Fig. (1). The bridge width was $0.2 \mathrm{~mm}$, and the separation between potential contacts was $0.3 \mathrm{~mm}$. Twin boundaries in the bridge were oriented in the same direction. The bridge was cut so that the transport current vector I was parallel to twinning planes.

\section{Results and Discussion:}

Fig. (1) shows resistive transitions of the sample 1 measured tilted magnetic fields (curves $1-4$ ). Below $\mathrm{T}_{\mathrm{sh}} \approx 88 \mathrm{~K}$ the downturn toward zero resistance is observed. Curve 5 displays the resistive transition of sample 2 in the field $\mathrm{H} \|$ c. Above $\mathrm{T}_{\text {sh }}$, CVCs were linear for both samples indicating unpinned state of vortices.

Fig. (2a) shows CVCs of sample 1 measured at temperatures below $\mathrm{T}_{\mathrm{sh}}$ for $\Theta=7^{\circ}, \Phi=0.0$ (curves 1-5) and for $\Theta=\Phi=0$ (curve $6)$. CVC for $\Theta=0$ is strongly nonlinear and hence vortices aligned parallel to TBs are in a pinned state. For $\Theta=7^{\circ} \mathrm{CVCs}$ are linear but the resistance $R_{1}=d V / d I$ is much smaller than the Barden-Stephen flux flow resistance $R_{B S}=R_{N} B / B_{c 2}$ (here $R_{N}$ is the normal state resistance and $\mathrm{B}_{\mathrm{c} 2}$ is the induction of the upper critical field). In magnetic fields tilted with respect to TBs, the vortex has the structure $^{(5)}$ shown in Fig. (2b). Since the part of vortex $r$ aligned with TBs is pinned, the resistance $\mathrm{R}_{1}$ may arise due to movement of the part 
of the vortex s placed out of TBs. In this case the part of vortex s may be considered as unpinned vortex fluid which possesses torsional rigidity due to pinning of the vortex parts $r$ aligned with TBs. Torsional rigidity associated with preserving orientation order may be the reason of linear resistance decreasing with the temperature decreasing.

Fig. (3a) shows CVCs of the sample 2 measured at temperatures below $\mathrm{T}_{\mathrm{sh}}$ for $\Theta=0$. Curves 1-5 were obtained for $\Phi=9^{\circ}$ and curves 6 and 7 were obtained for $\Phi=0$. The full set of CVCs for $\Phi=0$ is presented in Ref. 5. Initial parts of the curves are nonlinear due to thermally activated flux creep that occurs when the Lorentz force $F_{L}=I . B$ is smaller than the pinning force $F_{P}=I_{e d} B$, which is defined by the depinning critical current $\mathrm{I}_{\mathrm{cd}}$. At higher values of I linear or almost linear I - V curves are observed indicating the flux flow regime for $F_{L}>F_{p}$ or $I>I_{c d}$. In this regime, the derivative $d V / d I$ defines the flux flow resistance and extrapolation of linear parts of CVCs to $\mathrm{V}=0$ defines $\mathrm{I}_{\mathrm{cd}}$. Near $\mathrm{T} \approx 84.3 \mathrm{~K}$ we have obtained $\mathrm{R}_{f}(\Phi=0) \approx 4$ ohm.m and $\approx 4.5$ ohm.m, which are in good agreement with $\mathrm{R}_{B S} \approx 4.1$ m.Ohm. The depinning critical current for $\Phi=0$ is about 1.8 times smaller than for $\Phi=9^{\circ}$. For $\Phi=9^{\circ}$, the initial parts of CVCs are adequately described by the equation ${ }^{(6)}$.

$$
V=A \exp (-C / \sqrt{I})
$$

Where A and C are constants. Such dependence is predicted for vortex-glass phase for small currents. Initial parts of CVCs for $\Phi=0$ are best presented by Anderson-Kim flux creep model ${ }^{(7)}$.

$$
\mathrm{V}=\operatorname{Dexp}\left(-\mathrm{U}_{\mathrm{o}} / \mathrm{T}\right) \sinh \left(\mathrm{U}_{\mathrm{o}} \mathrm{I} / \mathrm{I}_{\mathrm{c}} \mathrm{T}\right)
$$

Where $I_{c}$ is the critical current, $U_{o}$ is the pinning potential, and $D$ is phenomenological parameter. Since for vortex-glass phase initial parts of CVCs are described by Eq.1, we think that this dependence may indicate existence of the vortex-lattice phase at low temperatures for $\mathrm{H}$ strictly parallel to $\mathrm{c}$-axis ${ }^{(2)}$. The rotation of magnetic field off TB planes gives rise to vortex-glass phase and enhances the value of $T_{c d}$. 


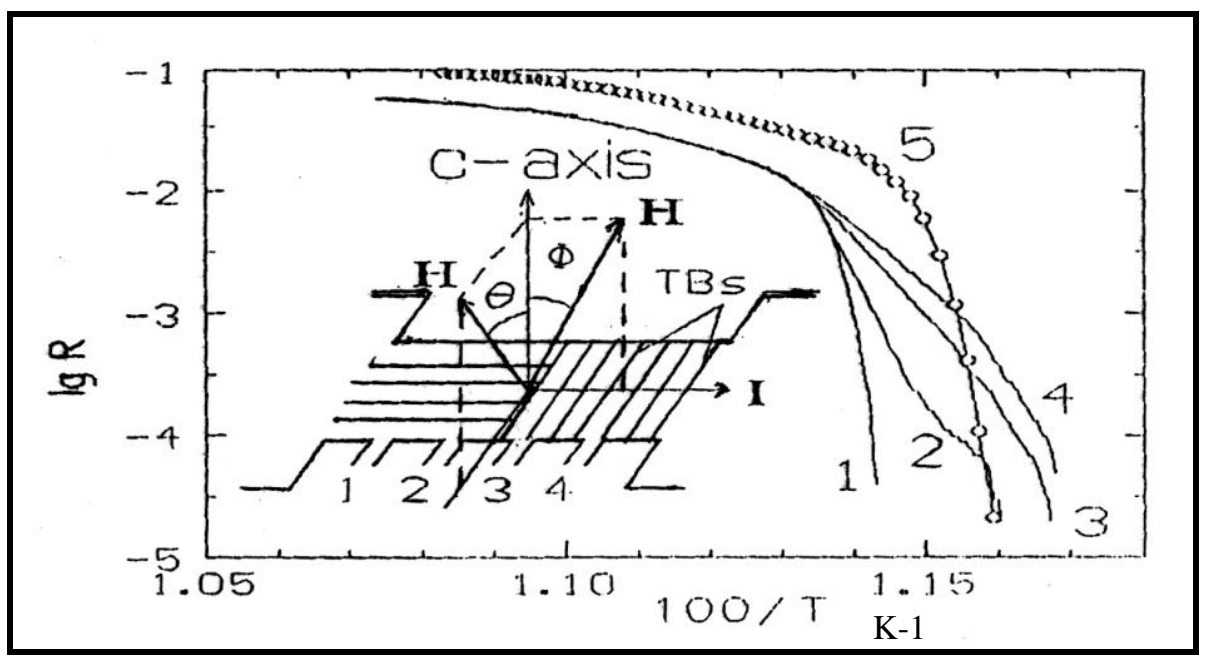

Fig. (1): Arrhenius plot of the resistive transitions of sample 1 (curves 1-4) and sample 2 (curve 5). Curves $1-4$ correspond to $\Theta=0,3^{\circ}, 7^{\circ}$ and $11^{\circ}$ respectively $(\Phi$ $=0$ ). Curves 5 was obtained for $\Theta=\Phi=0$. Inset shows the bridge which we have used and geometry of the experiment.

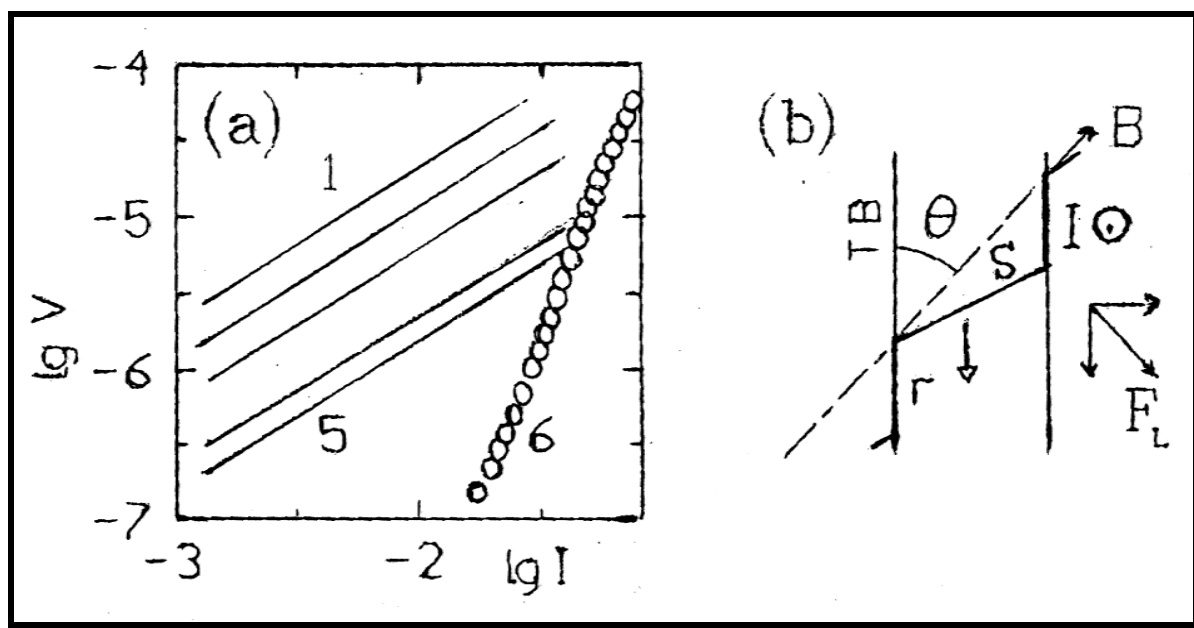

Fig. (2): (a) I-V curves of sample 1 measured for $\Phi=0$ and $\Theta=3^{\circ}$ at temperatures $\mathrm{T}=87.34,87.03,86.65,86.07$ and $85.47 \mathrm{~K}$ (curves $1-5$ respectively). Curves 6 measured for $\Theta=\Phi=0$ and $\mathrm{T}=87.31 \mathrm{~K}$. (b) The geometry of the vortex in tilted field, bold arrow shows the direction of the vortex movements. 


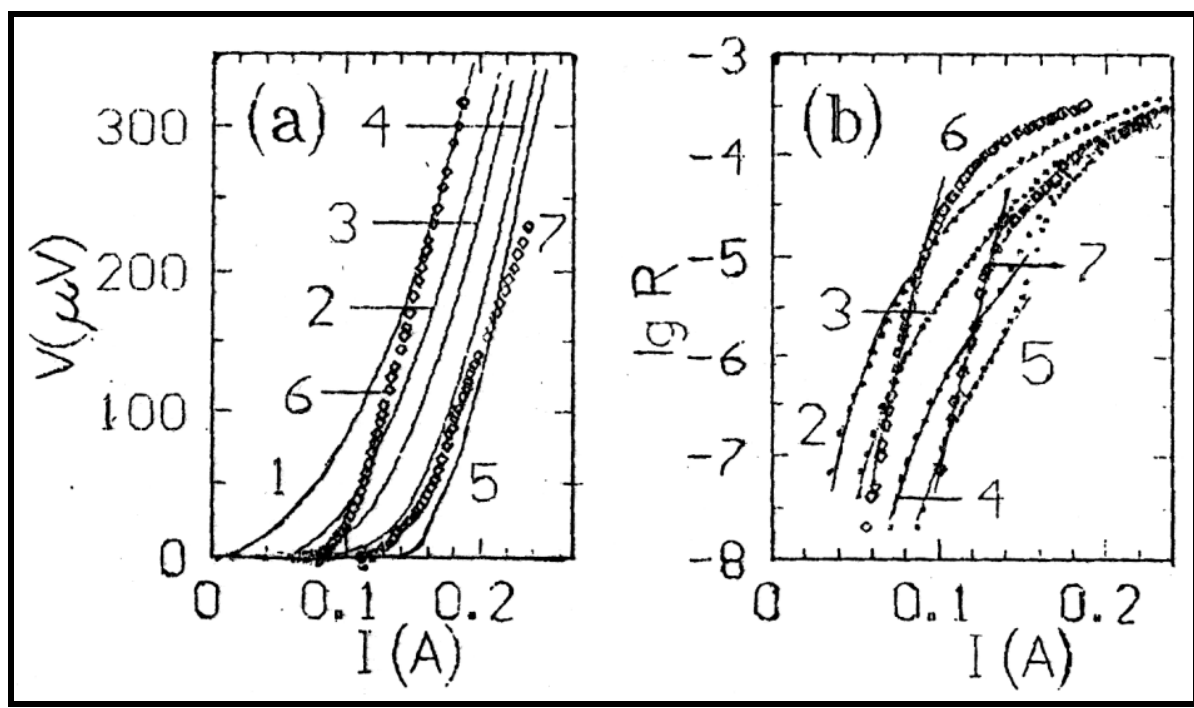

Fig. (3): Current-voltage characteristics of sample 2 measured for $\Phi=9^{\circ}$ and $\Theta=0$ at temperatures $\mathrm{T}=86.82,86.46,86.04,85.41,84.21 \mathrm{~K}$ (curves $1-5$ respectively) and for $\Theta=\Phi=0$ at temperature $\mathrm{T}=84.29$ and $81.81 \mathrm{~K}$ (curves 6 and 7 respectively). Solid curves in panel (b) are interpolation of initial parts of CVCs by Eq. 1 (for curves 2-5) and Eq. 2 (for curves 6 and 7).

The best fit of experimental curves with Eq. 2 at temperatures $\mathrm{T} \leq 82 \mathrm{~K}$ was obtained for $\mathrm{U}_{\mathrm{o}} \approx 1900 \mathrm{~K}$ and $\mathrm{D} \approx 10^{-4}$. For thermally activated hopping of flux lines or bundles over a pinning barrier we may write, ${ }^{(8)} \mathrm{D}=2 a N V_{o} B l$ and $\mathrm{U}_{\mathrm{o}}=\mathrm{BLV}_{\mathrm{c}} \mathrm{I}_{\mathrm{c}} / \mathrm{s}$ where $\mathrm{a}$ is the jumping distance, $\mathrm{N}$ is the number of vortices in a cascade, $V_{o}$ is the attempt frequency, $l \approx 0.2 \mathrm{~mm}$ is the length of the sample, $\mathrm{L}$ is the dimension of the pinning well, and $V_{c}$ is the activation volume. Supposing $\mathrm{L} \approx \xi 40 \mathrm{~A}$ ( $\xi$ is the Ginzburg-Landau coherence length), we obtain $\mathrm{V}_{\mathrm{c}}=10^{-19} \mathrm{~m}^{3}$ which is about 5 times greater than the volume of the flux line $\mathrm{V} \approx 2.10^{-20} \mathrm{~m}^{3}$. Supposing $\mathrm{a}=\mathrm{a}_{\mathrm{o}} \approx 360 \mathrm{~A}\left(\mathrm{a}_{\mathrm{o}}\right.$ is the separation between vortices) and $\mathrm{N} \approx 5$ we obtain $V_{o} \approx 10^{6} \mathrm{~Hz}$. This value is much smaller than the phonon frequency which we estimate to be about $10^{11} \mathrm{~Hz}$. 


\section{Acknowledgements:}

The author would like to thank M.A. Obolensky for comments and stimulating discussions of the data and A.V. Bondarenko for helping preparation the samples.

\section{References:}

1. V.M. Vinokur, V.B. Geshkernbein, A.I. Larkin, M.V. Feigel'man, Zh, Eksp. Teor. Fiz 65 (1990) 259.

2. T.K. Worthington, M.P.A. Fisher, D.A. Huse, J. Toner, A.D. Merrick, T. Label, C.A. Field, F. Holdtzberg, Phys. Rev. B46 (1992) 11854.

3. M.C. Marchetti and D.R. Nelson, Phys. Rev. B42 (1990) 1910.

4. M.A. Obolensky, A.V. Bondarenko, M. El-Saadawy, Low Temp. Phys. 21, (1995) 917.

5. G. Blatter, J. Rhyner, V.M. Vinokur, Phys. Rev. B43 (1991) 7826.

6. T. Nattermann, Phys. Rev. Lett. 64 (1990) 2454.

7. P.W. Anderson and Y.B. Kim, Rev. Mod. Phys. 36 (1964) 39.

8. A.P. Malozemoff, T.K. Wortington, E.Zeldov, N.C. Yeh, M.W. Melfresh, and F. Holtzberg, Proc. Symp. Strong Correlation and Superconductivity, (May, 1989, Japan) p. 349.

* * *


الملخص

ديناميكية الدوامات و التيار ات الحرجة فى البلورة الأحادية YBaCuO ذات ثنائيات

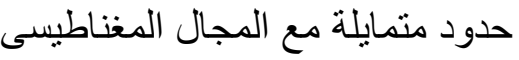

\section{د. محمد عبد اللطيف السعداوى}

تم قياس المقاومـة النوعية الانتقالية والمنحيات المميزة للجهد والتيار للبلورة الأحاديـة التى بها ثنائيات حدود موازية ومتعامة مـع متجة التيار الناقل فى وجود مجال

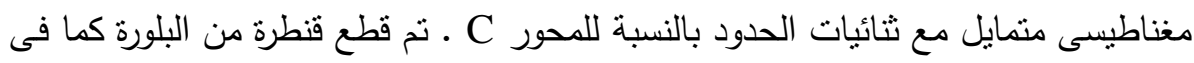

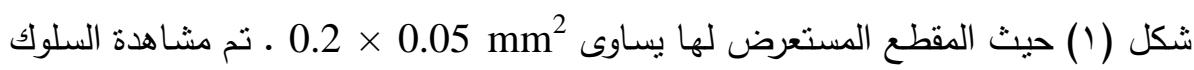
الزجاجى للدوامات عند التيارات الصغيرة لمتجه التيار المتعامد على مسنوى ثنايات الحدود. القياسـات تمت فى وجود مجال مغناطيسى H = 15kOe متجه التيار العابر (I) يكون

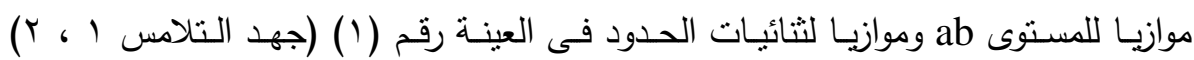

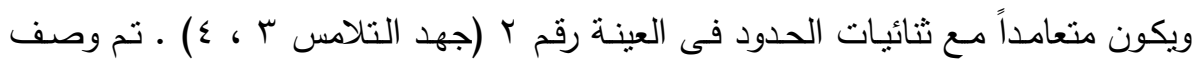

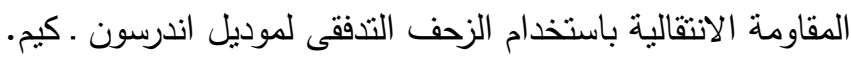

